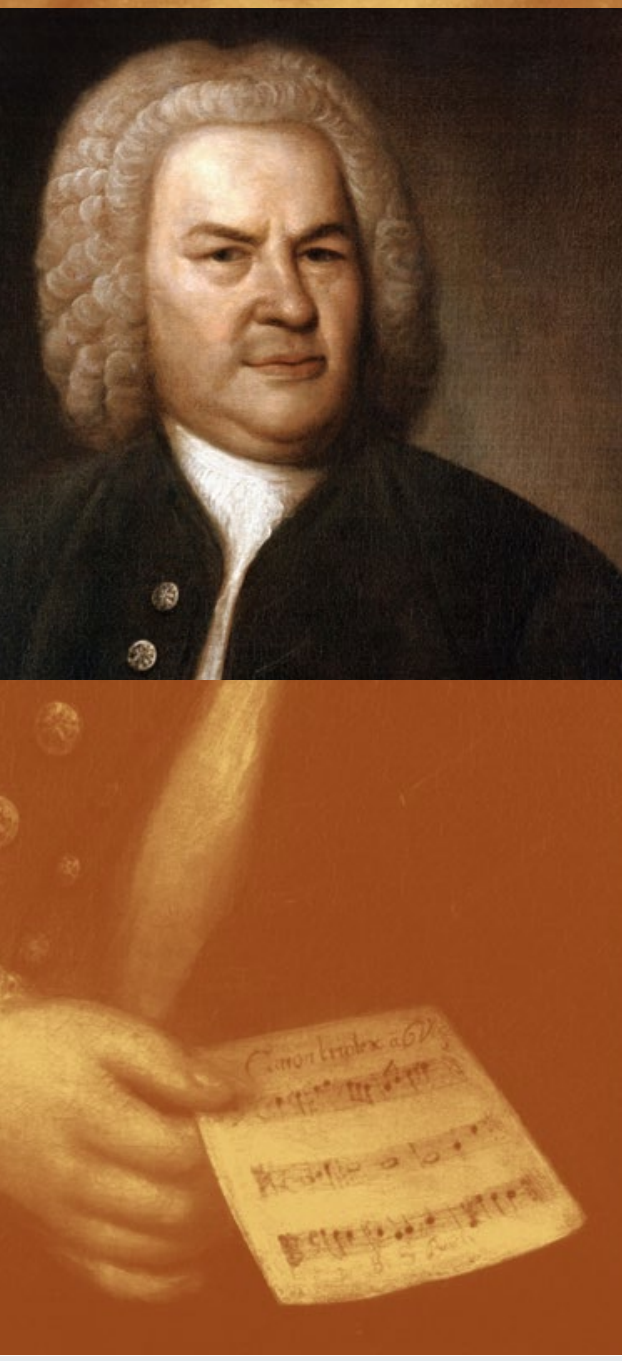

Prominente Patienten

Wussten Sie, warum Warhol stets grüne Baumwollunterwäsche trug? Was es mit dem „Einstein Sign“ auf sich hat? Und weshalb Schiller an der Fertigstellung von Goethes Faust zweifelte? Schauen Sie mit uns in die Krankenakten berühmter Persönlichkeiten.

\title{
Gespornter Musikus
}

\section{Johann Sebastian Bach}

\author{
Obwohl die Lage von Johann Sebastian Bachs Grab schon fast verges- \\ sen war, fand man sein Skelett mehr als 140 Jahre nach seinem Tod \\ wieder. Weitere 55 Jahre später machte ein Chirurg interessante Ent- \\ deckungen am Beckenring, an den Lendenwirbeln und Fersenbeinen.
}

A ls Johann Sebastian Bach (16851750) am letzten Julitag des Jahres 1750 auf dem alten Leipziger Johannisfriedhof beigesetzt worden war, wurde kein Grabstein errichtet. Wo sich sein Grab befand, geriet schnell in Vergessenheit. Es gab nur die mündliche Überlieferung und eine Steuernotiz, wonach der Sarg aus Eichenholz sechs Schritte vom Südtor entfernt in einer flachen Grube liegen solle.

37 Leichenköpfe halfen: 1894 begab man sich im Zusammenhang mit Umbauarbeiten des Kirchenschiffs auf die Suche nach den sterblichen Überresten. Tatsächlich fand man im Umkreis des Südeingangs drei Eichensärge. In einem davon befand sich ein „älterer, keineswegs sehr großer, aber wohlgebauter Mann“. Der Leipziger Anatomie-Professor Wilhelm His analysierte gemeinsam mit dem Professor für Zahnheilkunde Friedrich Ludwig Hesse den Schädel nach der Welcker-Profilmethode. Zuvor hatte sich His bei 37 Leichenköpfen von Männern in Bachs Alter und von seiner Statur Klarheit darüber verschafft, welche Weichteildicken den Gesichtsknochen an verschiedenen Stellen aufliegen. Vom Bildhauer Carl L. Seffner ließ er das Gesicht rekonstruieren, um es mit historischen Abbildungen vergleichen und die Frage beantworten zu können: Ist das Bachs Skelett oder nicht? His' Gutachten lautete, dies sei „in hohem Grade wahrscheinlich“. Sein Befund wurde später mehrfach bestätigt.

Bei der Umbettung 1949 hatte der Berliner Chirurg Wolfgang Rosenthal erneut Gelegenheit, die Gebeine des Thomaskantors in Augenschein zu nehmen:
„Ich hatte ... den Eindruck einer multiplen Exostosen-Bildung am Beckenring, an den Lendenwirbeln und an den Fersenbeinen“. „Auffallend kräftig hervorspringend waren auch die Muskellinien am Oberarm- sowie an den Unterarmknochen. Es machte den Eindruck, dass der Inhaber sich mit seinen Armen bei Lebzeiten von Jugend an kräftig betätigt hätte." Die immer wiederkehrenden Muskelaktivitäten beim Orgelspiel haben nach seiner Ansicht an den Muskelansätzen besonders des Schambeins diese Exostosen hervorgerufen. Rosenthal verweist darauf, dass die Orgeln zu Bachs Zeiten oft sehr schwer spielbar gewesen sein müssen, man sprach vom „Orgelschlagen“.

Organistensporne als Beweis: Die gleichen Exostosen hat Rosenthal beim Leipziger Thomaskantor Günther Ramin (1898-1956) röntgenologisch nachgewiesen. Die „schwebende“ Haltung des Organisten auf seiner Bank bei fortwährender Aktion der Beine und Füße und gleichzeitiger Aktion an den Manualen bedarf einer ständigen und repetitiven Aktion der Rumpf-, Oberschenkel- und Wadenmuskulatur. Diese könnten die Knochenveränderungen an den Schambeinen, den unteren Lendenwirbeln sowie den Fersenbeinen erklären. Ähnliche Befunde fand Rosenthal bei zehn weiteren Organisten und spricht von „Organistenspornen“. „[Ich] zweifle nicht mehr daran, dass es eine ,Organistenkrankheit' gibt“, schrieb er. Rosenthal sah die Kochenbefunde als weiteren Beweis dafür an, dass das 1894 gefundene Skelett tatsächlich das des Komponisten gewesen sein muss.

Thomas Meißner 